\title{
ASPECTOS JURÍDICOS E CRIMINOLÓGICOS DA PRÁTICA DE HOMICÍDIOS POR MOTIVOS CULTURAIS INDÍGENAS
}

\author{
Tainá Fernanda Pedrini* \\ Pollyanna Maria da Silva**
}

\begin{abstract}
Resumo: O homicídio de crianças indígenas, motivado culturalmente, contrapõe os direitos à vida e à diversidade cultural. Sob a perspectiva antropológica, criminologia e jurídica, objetivase discutir esta prática. Utiliza-se o método indutivo e a técnica da pesquisa bibliográfica. Conclui-se que, nestes casos, o direito à vida não pode ser relativizado. Pessoas vulneráveis não podem ser mortas em nome da identidade cultural indígena. Contudo, o Estado não pode intervir diretamente diante da ocorrência de homicídios motivados por questões culturais praticados nas aldeias indígenas. Em face disso, emerge a necessidade de políticas públicas que, respeitando o direito à identidade cultural, desestimulem tal prática.
\end{abstract}

Palavras-chave: Índios; Multiculturalismo; Pluralismo jurídico; Homicídio.

\section{LEGAL AND CRIMINOLOGICAL ASPECTS OF THE PRACTICE OF MURDER FOR INDIGENOUS CULTURAL REASONS}

\begin{abstract}
The murder of indigenous children, culturally motivated, contrasts the rights to life and cultural diversity. From the anthropological perspective, criminology and juridical, it aims to discuss this practice. The inductive method and the bibliographic research are used. It is concluded that, in these cases, the right to life can't be relativized. Vulnerable people can't be killed in the name of indigenous cultural identity. The State can't intervene directly in the face of murders motivated by cultural issues in indigenous villages. On the face of it, the need for public policies that, respecting the right to cultural identity, discourage such practice.
\end{abstract}

Keywords: Indians; Multiculturalism; Legal pluralism; Murder.

\footnotetext{
* Mestranda em Ciência Jurídica pela Widener University, Delaware Law School e pela Universidade do Vale do Itajaí. Pós-graduanda em Direito Tributário pelo Instituto Brasileiro de Estudos Tributários e em Direito Registral de Notarial pela Faculdade Damásio. E-mail: tainapedrini @live.com..Endereço postal: Rua Mário Vinotti, n 170, apartamento 602, Centro II, Brusque, Estado de Santa Catarina, CEP 88353-131.

** Mestre em Ciências Criminais pela PUC/RS. Professora de Direito Penal na UNIVALI - Universidade do Vale do Itajaí e no Centro Universitário de Brusque. E-mail: pms.br@hotmail.com. Endereço postal: Rua Timbó 283, ap. 403, Victor Konder, Blumenau/SC - CEP 89012
}

Rev. de Criminologias e Politicas Criminais | e-ISSN: 2526-0065 | Porto Alegre | v. 4 | n. 2 | p. 81 - 101 | Jul/Dez. 2018 


\section{INTRODUÇÃO}

Os Índios acreditam que um ser somente se torna humano após a troca de experiências com os demais. Logo, não é o momento do nascimento que o torna parte integrante da comunidade. Ao emergir, indígenas inspecionam o nascituro: é ele um humano? Ou algum animal que a tribo não conhece? Caso esta premissa seja verdadeira, este deve ser expulso o mais rápido possível, mediante o homicídio - praticado geralmente pelas mães após o parto vez que a comunidade acredita correr risco de ser amaldiçoada. $\mathrm{O}$ mesmo ocorre com os gêmeos, deficientes físicos ou mentais, provenientes de mães solteiras, entre outros.

Tal conduta é tipificada pelo Código Penal, classificando-se como um crime culturalmente motivado. A conjuntura contrapõe dois direitos fundamentais: o direito à vida e à diversidade cultural, o que enseja o estudo acerca dos limites das posições subjetivas de cada uma destas garantias, assim como, a possibilidade de disposição destas e seus efeitos no plano jurídico e fático.

Destaca-se que a maior parte das pesquisas, bem como, os projetos legislativos tratam a conduta cultural discutida sob o tema "infanticídio indígena", denominação que não foi acompanhada nesta pesquisa. Isso porque tecnicamente a morte de crianças, nessas condições, não pode ser considerada infanticídio, mas tão somente homicídio, segundo o disposto no artigo 123 do Código Penal.

Diante disso, objetiva-se analisar a prática de homicídios direcionados às crianças indígenas motivados por questões culturais. Para alcançar este objetivo adotam-se os conceitos de Pluralismo Jurídico e direito consuetudinário indígena, a fim de sopesá-los à luz da proteção constitucional conferida ao direito à vida e a identidade cultural indígena.

Não existem números oficiais de quantas crianças são mortas anualmente no Brasil por questões culturais. Contudo, sabe-se que são centenas. Entre os Yanomami, por exemplo, temse o infanticídio como principal causa de morte de crianças com menos de um ano de idade, sendo que nos anos de 2004 e 2005, por exemplo, 166 foram mortas. Tais informações, evidenciam a gravidade do problema e, consequentemente, a relevância da temática abordada (BARRETO, 2006).

Diante disso, levantam-se as seguintes problemáticas: O homicídio de crianças indígenas pode ser considerado uma questão cultural? Há razões para a manutenção destas práticas? Em nome da preservação da tradição o direito à vida pode ser violado? O Estado deve 


\section{ASPECTOS JURÍDICOS E CRIMINOLÓGICOS DA PRÁTICA DE HOMICÍDIOS POR MOTIVOS CULTURAIS INDÍGENAS}

interferir na prática de manifestações culturais nocivas à sobrevivência individual e coletiva? O método utilizado foi o indutivo, com acionamento da técnica e da pesquisa bibliográfica.

\section{ASPECTOS GERAIS ACERCA DO CULTURAL DEFENSE}

A cultura de uma Sociedade pode ser entendida como um conjunto de símbolos, incluindo-se padrões de comportamento, seus valores materiais e espirituais, bem como suas instituições. Esses símbolos, criados pelo próprio povo que os vivenciam, conferem-lhe sentido, originam suas regras próprias e seus costumes e, ao final, servem de identificação devido às suas idiossincrasias (JUNQUEIRA, 2008).

Já a etnia “significa 'gentio', proveniente do adjetivo grego ethnikos. O adjetivo se deriva do substantivo ethnos, que significa gente ou nação estrangeira" (SANTOS, 2010). Trata-se de "um conceito polivalente, que constrói a identidade de um indivíduo resumida em: parentesco, religião, língua, território compartilhado e nacionalidade, além da aparência física" (SANTOS, 2010, p.121). Consiste na crença comum de uma Sociedade, sendo desnecessário que este povo seja descendente de uma comunidade originária, mas tão somente que compartilhe seus costumes.

Salienta-se que a cultura e, logo, as etnias têm caráter dinâmico, transformando-se constantemente, isto é, elas evoluem no tempo, não necessariamente como um todo, mas em escalas. É natural também que cada cultura se considere “como a 'verdadeira' expressão da humanidade, desqualificando as demais, que não passam, a seu modo de ver, de imperfeitas, primárias; quando não, selvagens e bárbaras" (JUNQUEIRA, 2008, p. 17). Diante disso, tomam como irrelevantes as regras prescritas e os costumes levados por outros povos.

Esse cenário de coexistência entre grupos culturais, denominado Multiculturalismo, traz à tona a relação entre a cultura e o Direito penal, que origina outras nomenclaturas, como, por exemplo, os "delitos culturalmente motivados" e a cultural defense.

Analisa-se "a ideia de multiculturalismo, a partir de uma constatação descritiva da realidade" (SARAMENTO, 2013, p. 4), pois “as sociedades modernas se veem marcadas pela coexistência de diferentes grupos étnicos, religiosos e culturais. Isso porque, subsistem num mesmo espaço diversas culturas e visões de mundo" (SARAMENTO, 2013, p. 5). A fim de conceituar o termo, entende-se por Multiculturalismo a coexistência de múltiplos traços culturais inseridos dentro de um mesmo Estado e espaço de tempo. Incluídas neste conjunto

Rev. de Criminologias e Politicas Criminais | e-ISSN: 2526-0065 | Porto Alegre | v. 4 | n. 2 | p. 81 -101 | Jul/Dez. 2018 
multicultural estão as minorias étnicas, como é o caso dos negros, dos refugiados e dos indígenas.

Salienta-se que a própria globalização traçou a necessidade de flexibilizar a intransponibilidade das fronteiras territoriais e ofertar harmonia e solidariedade entre os povos. Nesse sentido, o Multiculturalismo não está somente adstrito a ideia de uma Nação, mas também a seu contexto transnacional diante das relações de poder estabelecidas entre os países, como é o caso do antigo eurocentrismo e a atual americanização da economia.

Os delitos culturalmente motivados revelam, inicialmente, a existência de um Pluralismo Jurídico. Consubstanciam-se em determinados comportamentos realizados por um grupo minoritário que contradizem a norma penal de um grupo majoritário, motivados em razão da cultura dos infratores. Nasce, portanto, um conflito entre o respeito aos valores compreendidos dentro da cultura deste grupo minoritário em detrimento ao disposto da legislação penal imposta de forma abstrata pelo Estado. (BROECK, 2001, p. 5)

Por conseguinte, verifica-se que o cultural defense se trata da ocorrência de certos fatores ou circunstâncias que permitem excluir ou diminuir a responsabilidade penal do agente quando observada alguma roupagem cultural por detrás de sua conduta (ASHWORTH, 2003, p. 97-98). Tal possibilidade, ao aplicar-se no ordenamento jurídico brasileiro, pode resultar em absolvição do acusado ou refletir no tempo da pena como atenuante devido ao fator cultural, podendo ser considerado o previsto nos artigos 65 , inciso III, alínea "a" ou 66 - ambos do Código Penal.

Dessa forma, constatando-se um delito culturalmente motivado, a cultural defense aplicar-se-ia de forma ampla ou restrita. É importante ressalvar ainda que os valores devem ser sopesados ao utilizar dessa possibilidade de redução ou extinção de pena. "Os fatores culturais não seriam relevantes em caso de violação de bens personalíssimos e indisponíveis como, por exemplo, a vida [...]”. (MAGLIE, 2012, p.144) Na realidade, parte da doutrina jurídica entende que não são passíveis dessa concessão "todos os bens tutelados direta ou indiretamente por tipos voltados a tutela dos direitos humanos" (MAGLIE, 2012, p.144), tendo em vista sua prevalência universal e sua característica de pertencer a própria existência humana, evitando-se assim, abusos desse privilégio jurídico direcionado às culturas minoritárias.

Nesse contexto multicultural, realiza-se o corte epistemológico na minoria representada pelos Índios no Brasil, especialmente no que tange ao Homicídio de Crianças Indígenas por questões de deficiência física ou mental, em caso de gêmeos, crianças provenientes de mulheres 
solteiras, dentre outros motivos culturalmente enraizados, que serão abordados nos tópicos posteriores.

\section{COMUNIDADES INDÍGENAS NO BRASIL}

Milênios antes do início da colonização portuguesa, no século XVI, o Brasil era habitado por povos indígenas. Frente a discrepância de costumes, os anos de 1500 a 1822 foram marcados, entre outros fatores, pela imposição da religião católica aos Índios, utilização da mão de obra nativa nos engenhos de açúcar e na extração de especiarias e demais riquezas.

$\mathrm{O}$ massacre realizado à época e a sujeição dos Índios à escravidão reduziram expressivamente seu número, especialmente por práticas abortivas realizadas pelas índias "que preferiam matar seus filhos a vê-los padecer como servos" (HOLANDA, 2008, p. 93).

Ao longo dos séculos, tal fato foi somado ao fracasso do Estado "no cumprimento das suas obrigações e de sua incapacidade de realizar o que não é mais do que seu próprio projeto de Nação" (SEGATO, 2014, p. 81) Rita Laura Segato (2014, p. 81) explica que isto ocorre porque, além de restringir a cultura indígena, o Estado não é capaz de oferecer oportunidades e condições dignas para a subsistência destas comunidades diante da nova realidade por ele imposta.

Isto é, os costumes indígenas foram moldados pelo Estado visando garantir unicidade territorial, política, jurídica e econômica ao longo dos anos, integralizando-os e assimilando-os aos demais povos residentes do Brasil, com o fito de homogeneizar a cultura nacional. Embora, concomitantemente, o índio integrado não obteve acesso a terras, saúde, educação e trabalho digno. "A integração passou a ser o discurso culto dos textos e das leis, enquanto na prática, a cordialidade de integração se transformava na crueldade da discriminação". (SOUZA FILHO, 2009, p. 63).

Diante das incessantes adversidades registradas pela história ${ }^{1}$, atualmente tem-se “aproximadamente 220 sociedades indígenas e um número total de 800 mil indígenas $(0,5 \%$ da população brasileira)" (SEGATO, 2014, p. 69). Ressalta-se que, segundo dados do Instituto Brasileiro de Geografia Estatística (IBGE, 2012), entre os anos de 2000 e 2010, considerando

\footnotetext{
1 “[...] se depois nos servimos deles para as nossas lavouras; nenhuma injustiça lhe fazemos; pois tanto é para os sustentarmos a eles e a seus filhos como a nós e aos nossos; e isto bem longe de os cativar, antes se lhes faz um irremunerável serviço em os ensinar a saberem lavrar, plantar, colher e trabalhar para seu sustento, coisa que antes que os brancos lho ensinem, eles não sabem fazer [...]” (VILLAS BÔAS FILHO, 2006, p.78).
}

Rev. de Criminologias e Politicas Criminais | e-ISSN: 2526-0065 | Porto Alegre | v. 4 | n. 2 | p. 81 - 101 | Jul/Dez. 2018 
a situação do domicílio, percebeu-se que nas áreas urbanas a população indígena decresceu como um todo, sendo a Região Norte a única brasileira, praticamente, que revelou crescimento positivo. Diferentemente ocorre nas áreas rurais, vez que o Brasil obteve crescimento de 151,9 mil indígenas, o que corresponde a 43,3\%. Dividindo-se o Brasil em regiões, a Norte foi, novamente, a que apresentou maior desenvolvimento, 77 mil indígenas, enquanto a Sudeste perdeu quase 2 mil.

Revela-se, portanto, um crescimento destes povos no país comparado ao período de colonização do Brasil e de política assimilacionista. Tal desenvolvimento é conhecido como "etnogênese" ou "reetinização":

[Os] povos indígenas que, por pressões políticas, econômicas e religiosas ou por terem sido despojados de suas terras e estigmatizados em função dos seus costumes tradicionais, foram forçados a esconder e a negar suas identidades tribais como estratégia de sobrevivência - assim amenizando as agruras do preconceito e da discriminação - estão reassumindo e recriando as suas tradições indígenas. Esse fenômeno está ocorrendo principalmente na região Nordeste e no sul da região Norte, precisamente no estado do Pará. (SANTOS, 2006)

Assim, apesar de a história revelar a alarmante diminuição destes povos, percebe-se hoje que devido as pressões realizadas pelas instituições brasileiras a fim de preservar essas comunidades, bem como, seu direito à diversidade, a população indígena tem apresentado significativo aumento em seu número, significando um fator positivo para a preservação da cultura.

\section{A PRÁTICA DE HOMICÍDIO DE CRIANÇAS NAS COMUNIDADES INDÍGENAS}

Para os indígenas não há qualquer liame entre o nascimento e a constatação de humanidade de uma criança, assim como, laços consanguíneos não constituem fator gerador de parentesco. Isto se faz pelas trocas de experiência e pelas relações sociais com a comunidade. Trata-se de um aprendizado diário de como fazer parte da tribo: o saber agir dentro das limitações prescritas e a sociabilidade determinará o papel do ser que acabou de nascer, bem como sua condição de humano. (VILAÇA, 2016)

O feto só pode ser conhecido após ter emergido espontaneamente, e somente então pode-se dar uma resposta satisfatória à questão crucial: "Ele é Humano?" O recémnascido é inspecionado visualmente em busca de evidências de sua identidade. Muitos fetos, ao emergirem, revelam-se não-humanos: formaram-se como jabotis, peixes, ou "algum animal que não reconhecemos". Eles não têm futuro no mundo da Humanidade, e são expulsos do espaço humano o mais rápido possível. (GOW, 1997) 


\section{ASPECTOS JURÍDICOS E CRIMINOLÓGICOS DA PRÁTICA DE HOMICÍDIOS POR MOTIVOS CULTURAIS INDÍGENAS}

Outro aspecto considerado relevante por estas comunidades é o recebimento de um nome cujo significado orientará o sujeito ao longo da vida (BONAMINGO, 2006, p. 94). Para recebê-lo, no entanto, o neonato deve demonstrar sua potencialidade em tornar-se social e humano. Desta forma, "alguns requisitos são necessários para que seja nominado como saber andar, falar ou alimentar-se com certa autonomia”. (HOLANDA, 2008, p. 27).

Para os Índios, o físico do feto, bem como sua total sanidade mental é de suma importância, não somente para conviver em Sociedade como também para participar dos rituais de passagem e alcançar o prestígio entre os demais indígenas. (VIDAL, 1977, p. 89). As crianças que apresentarem alguma deficiência mental ou física são mortas, pela mãe na maioria dos casos, por meio de práticas cruéis, isto é, são enterradas vivas, abandonadas na floresta ou envenenadas ${ }^{2}$.

Além disso, os gêmeos também não são considerados legítimos para conviver nas tribos indígenas. Aceitar sua coexistência significa amaldiçoá-las, provocando a ira de entes transcendentais, vez que algumas comunidades relacionam o nascimento de dois filhos de forma concomitante com a promiscuidade da mulher (HAKANI, 2016), somando-se a dificuldade de zelo e cuidado com os gêmeos. Da mesma forma os fetos que não tenham um pai reconhecido, isto é, os filhos de mãe solteira, também não são permitidos vez que representam uma grave ameaça aos costumes dos indígenas, devendo ser também sacrificados.

\footnotetext{
Cabe ao pai, principalmente, a responsabilidade social pela transformação pública do filho de "corpo aberto" em um parente de "corpo fechado", ou seja, um ser social. Um filho sem pai é o pior insulto possível para um Javaé e um motivo plenamente aceitável para o infanticídio. (HOLANDA, 2008, p. 61-62)
}

Além dos casos acima narrados, as índias igualmente matam a criança caso o sexo do filho não corresponda ao esperado, pois preferem que o primogênito seja do gênero masculino. Abre-se exceção às situações expostas havendo o nascimento de filho, principalmente no caso das mães solteiras, visto que dar à luz a um homem é motivo de orgulho, tanto às mães quanto aos pais.

Na realidade, há uma tendência generalizada destas tribos em promover homicídios de meninas. A prática do homicídio direcionada ao gênero feminino é reconhecida como

\footnotetext{
2 "Isso [a morte pelas mães] expressa a autonomia da mulher em decidir pela vida ou a morte do filho e funciona como uma forma de seleção para as malformações e para o sexo das crianças", esclareceu. Segundo ele [Erwin Frank], a índia se isola do grupo e entra na mata quando sente que vai dar à luz. Ali, sozinha, ela decide o destino do filho por diversas razões, sem a interferência de nenhum outro membro da comunidade, nem mesmo o marido. Ela cava um buraco no chão, coloca algumas folhas e tem o filho de cócoras. Um dos métodos para matar a criança é asfixiá-lo com folhas". (COMISSÃO PRÓ-YANOMAMI, 2015)
} 
ocorrência típica de tradições patriarcais, nas quais se prefere o masculino, bem como este obtém hierarquia ante as demais. No caso indígena, deve-se ao desempenho social que lhes é designado, os homens são considerados responsáveis pelo desempenho econômico da família, assim como, são colocados em posições vitais ao funcionamento de rituais ancestrais. Diante desse papel, reserva-se às mulheres "apenas a função de subordinadas aos homens, peso financeiro e até sua definição em vário texto sagrados como uma propriedade”. (ADINOLFI, 2016, p. 4).

Ocorre que os sacrifícios de crianças indígenas diante de suas diferenças tem sido alvo de constantes discussões sob a ótica antropológica e jurídica. Da mesma forma, indivíduos de origem indígena que conseguiram salvar seus filhos da morte almejada pela tribo, atualmente, participam de projetos $^{3}$ que visam eliminar tal prática cultural. Assim, discute-se primordialmente a coalizão entre o direito à vida e a aplicação da diversidade cultural indígena, aspectos que serão discutidos nos tópicos posteriores.

\section{ASPECTOS JURÍDICO-PENAIS DO INDÍGENA}

Os resultados mortes acima expostos decorrem de crenças milenares dos povos indígenas, e suas "formas tradicionais de controle relacionadas à própria necessidade de reprodução da vida" (CIRINO, 2013, p. 335). Como visto anteriormente, as comunidades indígenas já sofreram diversas afrontas aos seus direitos mais primitivos, v.g., a vida e a integridade física. Pode-se dizer, portanto, que a consciência social em, ao menos, garantir-lhes direitos somente adveio com a promulgação da Constituição da República Federativa do Brasil de 1998 (CRFB/88) e a consequente inovação legislativa ordinária posteriori.

As primeiras evoluções garantistas podem ser percebidas no artigo 216 da CRFB/88 (BRASIL, 1988) e seguintes, quando firmou-se a coexistência de diversos grupos sociais na formação da Sociedade brasileira e, logo, adjetivou o país como multicultural. Por conseguinte, o Estado assume a posição de protetor das "manifestações das culturas populares, indígenas e afro-brasileiras, e das de outros grupos participantes do processo civilizatório nacional" bem

\footnotetext{
${ }^{3}$ Quais sejam: o projeto de lei 295/2009 proposto por Aloizio Mercadante, o projeto de Emenda Constitucional 303/2008 de Pompeo Mattos e o projeto de lei 1067/2007, conhecida como "Lei Muwaji", criado por Henrique Afonso.
}

Rev. de Criminologias e Politicas Criminais | e-ISSN: 2526-0065 | Porto Alegre | v. 4 | n. 2 | p. 81 - 101 | Jul/Dez. 2018 


\section{ASPECTOS JURÍDICOS E CRIMINOLÓGICOS DA PRÁTICA DE HOMICÍDIOS POR MOTIVOS CULTURAIS INDÍGENAS}

como certifica aos Índios o ingresso, no ensino fundamental, segundo técnicas de aprendizagens próprias e conforme sua língua nativa.

Percebe-se claramente o contrate estabelecido pelo constituinte de 1998 em ruptura à política assimilacionista da época. Nesse sentido, a autodeterminação dos povos indígenas também foi reconhecida, nos artigos 231 e 232 da CRFB/88 (BRASIL, 1988), respectivamente, assegurando-lhes a diminuta interferência do Estado com relação a sua "organização social, costumes, línguas, crenças e tradições, e os direitos originários sobre as terras que tradicionalmente ocupam, competindo à União demarcá-las, proteger e fazer respeitar todos os seus bens". Não só a identidade cultural própria foi consolidada, como também a possibilidade de ocuparem o pólo ativo em demandas judiciais visando defender "seus direitos e interesses, intervindo o Ministério Público em todos os atos do processo".

A Constituição de 1988 reconhece aos índios o direito de ser índio, de manter-se como índio, com sua organização social, costumes, línguas, crenças e tradições. Além disso, reconhece o direito originário sobre as terras que tradicionalmente ocupam (SOUZA FILHO, 2009, p. 107).

No que tange a aplicabilidade e vigência de direitos indígenas, estes são asseverados por Tratados e Convenções Internacionais, destacando-se a Convenção 169 da Organização Internacional do Trabalho (OIT), com caráter de norma supralegal. Já nos seus primeiros artigos, reafirma a necessidade de proteção e manutenção da cultura indígena e de seus territórios, resguardando-os de quaisquer formas de discriminação. O Estado é responsável por integrá-los e ouvi-los em casos que envolvem seus direitos, fazendo-os representar por instituições específicas - no caso brasileiro pela FUNAI e Fundação Nacional da Saúde (FUNASA), $v \cdot g$.

Ao tratar da responsabilidade penal do índio, a Convenção sobre os Povos Indígenas e Tribais (OIT, 1989) estabelece o respeito nacional pelos métodos que estes povos utilizam para reprimir os delitos cometidos por seus membros, na medida em que isso for compatível com o ordenamento jurídico e com os direitos humanos reconhecidos pelo país. De acordo com seu artigo $9^{\circ}$, os costumes indígenas devem ser considerados pelas autoridades e tribunais quando estes forem solicitados para se pronunciarem a respeito de questões penais destas comunidades.

Já o artigo 10 reforça a questão serem consideradas as características econômicas, sociais e culturais dos Índios ao aplicar-lhe sanção penal imposta pela legislação geral, visto que é inegável a disparidade sociocultural em que se inserem. Assim, “dever-se-á dar preferência a tipos de punição outros que o encarceram" (OIT, 1989).

Rev. de Criminologias e Politicas Criminais | e-ISSN: 2526-0065 | Porto Alegre | v. 4 | n. 2 | p. 81 - 101 | Jul/Dez. 2018 
Outrossim, a Declaração Universal de Direitos Humanos (ONU, 1948) - ideal a ser atingido por todas as nações - convenciona a necessidade das nações empregarem todos os esforços possíveis para respeitar o direito à igualdade de todos perante a lei, rechaçando-se toda forma de discriminação, conforme artigo VII, bem como assegura a todo ser humano, dentre outros direitos, o desempenho de suas práticas culturais "indispensáveis à sua dignidade e ao livre desenvolvimento de sua personalidade".

Mais especificamente relacionado aos povos indígenas, no ano de 2007, aprovou-se a Declaração das Nações Unidas sobre os Povos Indígenas (ONU, 2007) motivada pelas injustiças históricas por estes sofridas e com o fito de reconhecer os direitos intrínsecos a estas comunidades, dentre eles "o respeito aos conhecimentos, às culturas e às práticas tradicionais indígenas". Além disso, visa oportunizar a promoção das garantias já firmadas, assegurando “o direito das famílias e comunidades indígenas a continuarem compartilhando a responsabilidade pela formação, a educação e o bem-estar dos seus filhos" desde que em conformidade com o direito das crianças.

Destacam-se desta Declaração: o artigo $7^{\circ}$ proíbe a transferência forçada de crianças indígenas para outro grupo; já o artigo 11 prevê o direito destas comunidades a "praticar e revitalizar suas tradições e costumes culturais. Isso inclui o direito de manter, proteger e desenvolver as manifestações passadas, presentes e futuras de suas culturas [...]”, e, ainda; o artigo 22 direciona ao Estado a responsabilidade de proteger mulheres e crianças contra todas as formas de violência e discriminação.

Pode-se dizer, por fim, que a Declaração Universal sobre a Diversidade Cultural estabeleceu, no ano de 2011, com base nos direitos já amealhados a esta pesquisa, importantes evoluções que visam primordialmente a garantia dos direitos mais inatos ao homem, como é o caso da vida. Em seu artigo $4^{\circ}$, a Declaração busca defender a diversidade cultural, como regra geral, reafirmando o já estabelecido por outras legislações. Apesar disso, esta legislação trata a cultura indissociável aos direitos humanos, sendo assim, aduz que ninguém "pode invocar a diversidade cultural para justificar a violação dos direitos humanos garantidos pelo direito internacional, nem para restringir o seu âmbito" (ONU, 2007, p. 08-14). 
5 PRESERVAÇÃO DA IDENTIDADE CULTURAL INDÍGENA EM DETRIMENTO A INVIOLABILIDADE À VIDA HUMANA

O Supremo Tribunal Federal, no julgamento do Mandado de Segurança 23.452, no ano de 2000, declarou que nenhum direito fundamental pode ser considerado absoluto, isto é, pacificando a possibilidade de sua restrição ou relativização (BRASIL, 2000). Neste sentido, pode-se dizer que as garantias fundamentais encontram-se, em tese, em um mesmo plano jurídico de hierarquia, valendo a noção de assimetria tanto substantiva quanto funcional entre os direitos conflitantes na análise de cada caso concreto, bem como, as várias posições subjetivas existentes e neles contidas.

Até os dias atuais não foi possível chegar a um consenso com relação à terminologia de direitos fundamentais, quiçá com relação ao conceito e abrangência de sua indisponibilidade/inviolabilidade, bem como, a extensão de cada garantia estabelecida em seu rol, como é o caso do direito à vida. Entretanto, para a finalidade a que se destina a presente pesquisa, utiliza-se o conceito de direitos fundamentais como norma jurídica positivada em razão de seu relevante axioma social, de cunho intrinsecamente moral, dos quais analisados em conjunto, tornam-se um ideal de dignidade e respeito conferido a todo o ser humano, a serem protegidos pelo Estado.

Entende-se que os elementos que configuram o conteúdo mínimo de um direito fundamental - entendidos por parte da doutrina como intocáveis - estão condicionados ao contexto em que se aplicam e ao momento histórico analisado, por isso variam entre si. Além disso, as garantias constitucionais desempenham duas funções: objetiva e subjetiva. Aquela faz referência ao próprio ordenamento jurídico, do qual as normas não constitucionais encontram respaldo para a sua validade e existência. "Se trata de una función de carácter eminentemente "jurídica”. Y tiene que ver com El hecho de que los derechos fundamentales ocupan um puesto jerárquico muy elevado" (ALCALÁ, 2015. p 544). Já esta - utilizada pela pesquisa, discute até que ponto o Estado pode interferir na cultura de um povo para garantir os direitos fundamentais por ele impostos - relaciona-se com a práxis democrática constitucional e o sistema político vigente, direcionando-se diretamente ao Estado e seus representantes. "Esta función se traduce em que los derechos fundamentales se constituyen en um "límite" al ejercício de La actividade del poder" (ALCALÁ, 2015, p 544). 
É cediço que para restringir um direito fundamental necessita-se utilizar do princípio da proporcionalidade ${ }^{4}$, compreende a legitimidade do fim a que se destina a ablação da garantia, assegurando os meios idôneos - e o liame entre aquele e este -, além da impossibilidade de outra decisão menos gravosa. (PEREIRA, 2006, p. 324-346).

Os direitos contrapostos nesta pesquisa provêm diretamente da dignidade da pessoa humana. Esta se trata da (de)limitação da atuação dos poderes conferidos ao Estado e a Sociedade de forma abstrata, visando representar cada indivíduo em sua subjetividade e unicidade, ou mesmo, o ser humano como coletivo em sua totalidade. A dignidade não abarca somente dimensões defensivas, mas também implica em um dever prestacional de dignidade. “A pessoa não pode ser reduzida a condição de mero objeto da ação própria e de terceiros, mas também o fato de a dignidade gerar direitos fundamentais (negativos) contra atos que violem ou a exponham a graves ameaças" (SARLET, 2005, p. 32). O dever de prestação emana em decorrência de obrigações concretas “[...] de tutela por parte dos órgãos estatais, no sentido de proteger a dignidade de todos, assegurando-lhe também por meio de medidas positivas (prestações) o devido respeito e promoção”. (SILVA, 1998, p. 201).

Assim, a fim de atingir o cerne da questão, após delinear quais os direitos que estão em discussão - o direito à vida e à identidade cultural, é necessário discorrer o conceito e os limites das posições subjetivas de cada uma destas garantias, bem como a possibilidade de disponibilidade destes direitos e seus efeitos no plano jurídico e também fático, para que deste modo se possa visualizar adequadamente a resolução do conflito de normas, mediante o princípio da proporcionalidade e seus requisitos intrínsecos.

\subsection{Direito à vida}

A preocupação em garantir a vida de todo o ser humano ganhou ênfase com os estudos realizados pelo liberalista e jusnaturalista John Locke, que constituiu a tríade de direitos: vida, propriedade e liberdade. Apesar da incorporação destes direitos aos ordenamentos de diversos países - principalmente depois das revoluções populares v.g Revolução Francesa e Americana -, a busca pelo fortalecimento e a concretização do direito à vida somente ocorreu após o

\footnotetext{
${ }^{4}$ [...] o princípio da proporcionalidade supõe também interpretar os direitos fundamentais de proteção como princípios e aceitar que deles se deriva a pretensão prima facie de que o legislador os garanta na maior medida possível, tendo em vista as possibilidades jurídicas e fáticas. (PULIDO, 2007, p. 826).
} 


\section{ASPECTOS JURÍDICOS E CRIMINOLÓGICOS DA PRÁTICA DE HOMICÍDIOS POR MOTIVOS CULTURAIS INDÍGENAS}

holocausto gerado pelas Grandes Guerras, resultante de regimes totalitários que dizimaram milhões de pessoas e ceifaram suas liberdades. (WEINRIB, 2016).

Diante deste histórico, o direito à vida elevou-se a condição de absoluto e supremo. Conforme José Afonso da Silva (1997, p. 182), todo o ser depois de receber a vida eleva-se a condição de indivíduo, o que torna a coexistência entre ambos indissociável. Desta forma, passa a ser mais do que um indivíduo, mas também uma pessoa e, por isso, a vida "constitui a fonte primária de todos os outros bens jurídicos. De nada adianta a Constituição assegurar outros direitos fundamentais [...] se não erigisse a vida humana num desses direitos".

Na verdade, até os dias atuais, quando mencionado tal direito traz-se à lume - quase que irretocavelmente - a sua indisponibilidade. A um, porque é considerada a mais fundamental das garantias asseguradas pelo Direito, vez que é pré-requisito para a existência e o exercício de todos os demais. A dois, constitui-se da essência do homem como um ser sociável e político, vez que este se reveste de tal proteção jurídica desde a sua concepção até a morte, o que corresponde à valorização e respeito da Sociedade ao axioma que representa a vida humana.

Ronald Dworkin (2003, p.96) explana que a Sociedade como um todo acredita ser “intrinsecamente lamentável que vida humana, uma vez iniciada tenha um fim prematuro. Em outras palavras, acreditamos que uma morte prematura é intrinsecamente má [...]’'Isso porque na concepção social "uma coisa terrível acontece quando uma pessoa tira a própria vida, ou quando pede ao seu médico que a mate, ainda que a morte venha satisfazer um interesse fundamental" de determinado sujeito.

Dworkin (2003, p. 118) trata a vida humana, no que se refere à relevância, analisandoa em três planos: a) instrumental - considerando as modificações que o indivíduo visto como ser único realiza na vida da Sociedade; b) subjetivo - eleva-se a própria concepção pessoa acerca da importância de estar e permanecer vivo; c) pessoal - é a valoração do sujeito acerca do bem "vida". Utiliza-se desta diferenciação para saber "que direitos à vida têm diferentes tipos de pessoas, ou de quão negativa é a perversidade de negar-lhes os recursos que poderiam salvar suas vidas ou matá-las".

Percebe-se que a análise destes planos é realizada em cada caso concreto de forma diversa. Ao aplicar ao homicídio de crianças indígenas, percebe-se que as concepções descritas nos planos "b" e "c" não podem ser consideradas, visto que a consentimento do sujeito afetado não é válido diante da sua impossibilidade de percepção da realidade e inserção social deveras prematura - o mesmo emprega-se aos pais do sujeito vez que ninguém tem e titularidade dos direitos fundamentais de outrem, em regra, principalmente no que se refere à vida. Assim, 
analisar-se somente no que tange ao caráter instrumental da vida da criança indígena no seio social.

Percebe-se que o direito fundamental à vida é sui generis quanto ao seu núcleo. Isso porque tratando-se do direito de permanecer vivo ${ }^{5}$ não se pode vislumbrar um conteúdo acidental que circunde a essência deste direito, visto que o mínimo de restrição já estaria adentrando-o como um todo. A vida não se trata de um direito fundamental que se pode dispor parcialmente, tão-somente ao que se refere ao seu exercício - não compreende a possibilidade de retorno ao status quo da posição subjetiva. Ao abdicar desta garantia, o indivíduo também dispõe de sua própria titularidade, além de todos os outros direitos obtidos enquanto ser humano, inclusive, o direito pelo qual se reivindica em detrimento à vida, visto que se exaure a condição humana.

Utiliza-se em antítese a garantia discutida, o direito de morrer, que serve como explicação da redução da garantia em questão. Ocorre que em todos os casos analisados, este direito-antítese, para ser utilizado, carece de vários requisitos, dentre eles o consentimento válido e ciente do ser que dispõe das posições subjetivas do direito à vida. Nesse sentido, não se pode aplicar ao caso tal antítese a fim de justificar a sua ablação, vez que sequer são preenchidos os requisitos mínimos para o início da discussão.

Embora o conteúdo já discorrido demonstre a raríssima possibilidade de violar o direito à vida, é necessário frisar que enaltece-lo como inalterável e irretocável com o transcorrer dos anos tornou-se tarefa árdua diante de situações extremas, tal premissa de inviolabilidade tornouse discutível, formando-se algumas correntes doutrinárias que visam discorrer acerca de sua possível ablação em diversos casos, principalmente após a solidificação pelo STF de que nenhum direito fundamental é absoluto. Para tanto, utiliza-se do próximo tópico para explanar importância da identidade cultural indígena e, ao final, poder concluir qual direito apresenta (mais) vantagens formais ou materiais em detrimento ao outro - a vida ou a identidade cultural.

\section{$5.2 \mathrm{O}$ direito à identidade cultural}

A necessidade da efetiva manifestação da vontade do povo, compreendido em toda a sua pluralidade de composição, deu origem ao constitucionalismo, assim como as atrocidades

\footnotetext{
${ }^{5} \mathrm{O}$ significado do direito à vida, em sua essência, é designado por essa pesquisa como: o direito de permanecer vivo e o direito de ser salvo ou de não ser deixado à vulnerabilidade da morte.
}

Rev. de Criminologias e Politicas Criminais | e-ISSN: 2526-0065 | Porto Alegre | v. 4 | n. 2 | p. 81 - 101 | Jul/Dez. 2018 


\section{ASPECTOS JURÍDICOS E CRIMINOLÓGICOS DA PRÁTICA DE HOMICÍDIOS POR MOTIVOS CULTURAIS INDÍGENAS}

acometidas nas Grandes Guerras fizeram o globo observar e clamar pela positivação e, principalmente, a concretização de direitos que garantissem a dignidade da pessoa humana em razão das atrocidades decorrentes deste evento, o que deu início ao que conhecemos como neoconstitucionalismo.

Atualmente, defende-se um ideal de "novo constitucionalismo" ou "constitucionalismo pluralista" em razão das diversas modificações e emendas constitucionais a fim de assegurar o Multiculturalismo. Raquel Yrigoyen Fajardo (2012, p. 191) defende a existência deste novo marco de transformação constitucional em três ciclos: A um, refere-se ao constitucionalismo multicultural "la emergência del multiculturalismo y el derecho a la diversidade cultural em el marco del Estado que reconoce sociedade multiétnica y multicultural" A dois, direciona-se ao constitucionalismo pluricultural: "la nación multicultural al Estado Pluricultural, con pluralismo jurídico interno" e, a três, trata-se do constitucionalismo plurinacional o qual resume-se a um "Proyecto descolonizador. Estado Plurinacional, com pluralismo jurídico igualitário, que reconoce libre determinación a los pueblos indígenas o naciones originarias”.

Diante destas modificações que levam ao atual cenário constitucional-multiétnico, o direito à diversidade cultural está solidificado. Consiste em um direito concedido "a determinados grupos culturalmente diferenciados de que suas tradições, crenças, e costumes possam ser preservados e protegidos frente a movimentos de interculturalidade". (BONAVIDES, 1999. p. 488). Isto é, "ninguém pode ser obrigado a abster-se de possuir suas próprias tradições, crenças e costumes, ou mesmo de ser obrigado a aderir às tradições crenças e costumes de outros grupos". (BONAVIDES, 1999, p. 488).

$\mathrm{O}$ direito a identidade indígena encontra barreiras jurídicas ao colocar-se frente aos ordenamentos de diversos países, bem como a Tratados Internacionais de Direitos Humanos. No caso do homicídio de crianças indígenas, crime culturalmente motivado, parte da antropologia brasileira utiliza-se do direito à identidade cultural a fim de que permaneça tal prática (cultural defense), como é o caso da antropóloga Rita Laura Segato. A opinião contraposta afirma que esta problemática decorre do relativismo antropológico, posicionandose pela prevalência do direito à vida, corrente em que pertence o jurista Lênio Streck.

Rita Laura Segato (2014, p. 82) inicia sua defesa em relação à permanência da tradição indígena tratando da expressão "direito à vida", sob a ótica de seus dois diferentes sentidos, quais sejam a proteção individual do sujeito como cumpridor de suas obrigações e titular de direitos inatos ao homem e a vida do indivíduo como sujeito coletivo, "isto é, o direito à 
proteção da vida dos povos em sua condição de povos. [...] Porque um direito fundamental de toda pessoa é ter povo, pertencer a uma comunidade".

Rodrigo Mioto dos Santos (2016) igualmente defende a identidade cultural indígena embora sob a ótica do Pluralismo Jurídico. Para ele "os índios possuem o direito de ter direito", isto é, serem reconhecidos como sociedade complexa e autossuficiente, vez que "possuem organização social, cultural, crenças, tradições, princípios éticos, valores e direitos próprios”.

Nesta corrente, conhecida como relativista, acredita-se que a noção de direito está ligada aos sistemas vigentes em determinada Sociedade, sejam eles políticos, econômicos, culturais, sociais e morais. Diante disso, cada cultura em si contém seu próprio discurso acerca dos direitos fundamentais, que provém das características histórico-culturais a ela inerentes. Para eles, necessita-se respeitar as diferenças culturais, assim como seu sistema moral. (PIOVESAN, 2012, p. 215-216).

Em defesa da autonomia do indivíduo, Ronald Dworkin (2013. p. 100) afirma ser "vergonhoso que alguma forma específica de cultura humana, sobretudo uma cultura complexa e interessante, morra ou esteja em vias de desaparecer". O objetivo de toda a ideologia não é somente propagar a tradição já existente, mas também que ela permaneça aos seus descendentes, quando possível. Estas "culturas incorporadas" têm o desejo de continuarem sendo uma Sociedade distinta, autodeterminada e, inclusive, parte deste conglomerado de culturas que forma a Nação brasileira. (KYMLICKA, 1995, p. 19).

Por isso, Ronald Dworkin (2013, p. 342) conclui que a "liberdade é a exigência fundamental e absoluta do amor-próprio [...]. Para nós, o fato de viver de acordo com a nossa liberdade é tão importante quanto o fato de possuí-la”. Ressaltando-se que dispor o direito à vida em detrimento à identidade cultural, antes de tudo, é afirmar o direito geral de liberdade, que exclui a atividade estatal na intimidade privada.

Percebe-se que embora existam dois sentidos para o direito à vida, bem como, coexistam antinomias, no qual parte da antropologia jurídica entende pela prevalência do direito indígena quando aplicado aos seus povos, a opinião contrária argumenta que havendo problemas entre as normas indígenas e a legislação brasileira, aquela somente pode ser reconhecida enquanto não contrariar esta.

Deve haver um mínimo comum de valores à todas as culturas, os quais considera-se fundamentais, inderrogáveis e irredutíveis, independentemente dos próprios grupos e suas idiossincrasias. No caso em questão, conforme aborda Lenio Streck (2015) "não há motivo 


\section{ASPECTOS JURÍDICOS E CRIMINOLÓGICOS DA PRÁTICA DE HOMICÍDIOS POR MOTIVOS CULTURAIS INDÍGENAS}

algum para a aceitação dessa manifestação cultural numa sociedade que tem como princípio a proteção dos direitos e garantias fundamentais da criança":

Um multiculturalismo ingênuo, que naturaliza a morte de crianças (ou a ablação de mulheres na África), acaba caindo em um discurso puramente relativista [...]. Se a morte de crianças indígenas possui um sentido cultural [...] é importante lembrar que as execuções do Estado Islâmico, motivadas pela ortodoxia religiosa também o possuem. Mutilação de partes femininas, idem.

Não há possibilidade de assumir um discurso relativista, aceitando a normalização da prática de homicídio de crianças indígenas baseando-se na cultura. "Se tudo é cultural ou se a cultura tem o condão de superar a concepção de direitos humanos [...], então teríamos que achar um "natural-cultural" a descoberta de tribos que escravizam a outra" (STRECK, 2015). Diante do exposto, "a escravidão seria considerada cultural? [...]. No fundo, a pergunta que se põe é: a morte de crianças pode ser "uma questão cultural”?" (STRECK, 2015).

\section{CONSIDERAÇÕES FINAIS}

A vida de um ser humano é considerada de extrema relevância, devendo ser analisada prima facie como indisponível ante as demais garantias constitucionais. Tratando-se de pessoa vulnerável ou que careça de consentimento válido, como é o caso das crianças, não há possibilidade de disposição deste direito por outrem - isto é, por pessoas da tribo -, sendo a vida elevada ao mais alto grau de proteção. Diante disso, apesar de tal prática ser considerada cultural em razão da roupagem ideológica e geracional que carrega não há motivos para que seja mantida.

Ademais, em nome da identidade indígena não se pode relativizar-o direito à vida, principalmente, tratando-se de incapaz. Não se adentra na órbita da voluntariedade de sua disposição, isto é a autonomia do indivíduo em prol de uma crença própria, mas sim da disposição da titularidade da vida de outrem.

As comunidades precisam imediatamente ser amparadas por políticas públicas eficazes realizadas pelo Estado a fim de estimular o término dessas condutas, sem interferir nas demais. Ressalta-se que jamais poderá ser aplicado o encarceramento ao índio isolado ou em vias de integração, pois carecem da total noção da legislação brasileira, afrontando todos os tratados e convenções de direitos indígenas e, principalmente, a CRFB/88.

Diante do exposto, emerge a necessidade de continuação da pesquisa no sentido de avaliar as propostas legislativas em pauta no Congresso Nacional, bem como discutir políticas públicas que visem estimular o pensamento crítico dos povos indígenas em relação às condutas

Rev. de Criminologias e Politicas Criminais | e-ISSN: 2526-0065 | Porto Alegre | v. 4 | n. 2 | p. 81 - 101 | Jul/Dez. 2018 
direcionadas ao homicídio de crianças - que não apresentem as características para serem consideradas aptas à inserção no seio social indígena -, vez que tal prática geracional tem violado o direito à vida de tantas crianças no Brasil.

\section{REFERÊNCIAS}

ADINOLFI, Valéria Trigueiro. Enfrentando o infanticídio: bioética, Direitos Humanos e qualidade de vida das crianças indígenas. Disponível em: < http://www.redemaosdadas.org/wpcontent/uploads/2014/02/enfrentando_infanticidio-valeria_trigueiro.pdf $>$. Acesso em $01 \mathrm{fev}$. 2016.

ALCALÁ, J. Alberto Del Real. Análisis de los derechos fundamentales y de La plurinacionalidad em La Constitución boliviana de 2009. Anuario de Derecho Constitucional Latinoamericano - Anuario 2015. 648 p. Fundación Konrad Adenauer, Colômbia, 2015.

ALVES, Marina Vitório. Neoconstitucionalismo e novo constitucionalismo: características e distinções. Revista Seção Judiciária do Rio de Janeiro. Rio de Janeiro. v.9. n. 32, 2012.

ASHWORTH, Andrew. Principles of criminal law. 4 ed. New York: Oxford University Press, 2003.

BONAMINGO, Zélia Maria. A economia dos myba-guaranis: troca entre homens e entre deuses e homens na ilha de Cotinga em Paranaguá-PR. Universidade Federal do Paraná. (Dissertação de Mestrado em Ciências Humanas Letras e Artes). Curitiba, 2006. Disponível em:

http://dspace.c3sl.ufpr.br/dspace/bitstream/handle/1884/6054/Z\%C3\%A9lia\%20Maria\%20Bo namigo $\% 20$ Disserta\%C3\%A7\%C3\%A3o\%20Mbya-Guaranis.PDF?sequence $=1>$. Acesso em 29 jan. 2016.

BONAVIDES, Paulo. Curso de Direito Constitucional. 24 ed. São Paulo: Malheiros, 1999.

BRASIL. Câmera dos Deputados. Projeto de Lei n. 2.057, de 10 de outubro de1991. Dispõe sobre o Estatuto das Sociedades Indígenas. Diário do Congresso Nacional, Brasília, 9 nov. 1991.

Disponível

em: http://www.camara.gov.br/proposicoesWeb/fichadetramitacao?idProposicao=17569. Acesso em: 29 fev. 2016.

BRASIL. Constituição (1988). Constituição da República Federativa do Brasil. Brasília, Distrito Federal: Senado Federal: Centro Gráfico, 1988.

BRASIL. Decreto-lei $n^{o}$ 2.848, de 07 de dezembro de 1940. Código Penal. Rio de Janeiro, Disponível em: <http://www.planalto.gov.br/ccivil_03/decreto-lei/Del2848compilado.htm>. Acesso em: 05 ago. 2018.

BRASIL. Lei n. 6.001, de 19 de dezembro de 1973. Estatuto do índio. Lex: legislação federal e marginalia, Brasília, 1973. 
BRASIL. Superior Tribunal de Justiça. Recurso Especial n. 737.285. Disponível em: < https://ww2.stj.jus.br/processo/revista/documento/mediado/?componente=ITA\&sequencial=5 $92315 \&$ num_registro=200500493181\&data $=20051128 \&$ formato $=P D F>$. Acesso em: 29 fev. 2016

BRASIL. Supremo Tribunal Federal. Mandado de Segurança 23.452. Relator Ministro Celso de Mello. Data de Julgamento: 12 maio 2000.

BROECK, Jeroen Van. Cultural Defense and Culturally Motivated (Cultural Offences). v.9. European Journal of Crime. 2001.

CIRINO, Carlos Alberto Marinho. Criminalização de práticas culturais indígenas: o caso Yanomami. Ibero-Amerikanischen Institut. 2013.

CULVER, Keith. (Ed). Readings in the Philosophy of Law. 2 ed. Toronto: Broadview, 2008.

DWORKIN, Ronald. Domínio da vida: aborto, eutanásia e liberdades individuais. Tradução Jefferson Luiz Camargo. Revisão: Silvia Oliveira. São Paulo: Martins Fontes, 2003.

FAJARDO, Raquel Z. Yrigoyen. Pluralismo jurídico y jurisdicción indígena en el horizonte del constitucionalismo pluralista. Pluralismo jurídico y jurisdicción indígena. Biblioteca Jurídica Virtual del Instituto de Investigaciones Jurídicas de la UNAM, 2012. Disponível em: < http://biblio.juridicas.unam.mx/libros/8/3740/15.pdf>. Acesso em: 09 fev. 2016.

FUNDAÇÃO NACIONAL DO ÍNDIO. Modalidades de Terras Indígenas. Distrito Federal: FUNAI. Disponível em: < http://www.funai.gov.br/index.php/indios-no-brasil/terrasindigenas>. Acesso em 29 jan. 2016.

GOW, Peter. O parentesco como consciência humana: o caso dos piro. Rio de Janeiro: Mana, out. 1997. Disponível em: <http://www.scielo.br/scielo.php?script=sci_arttext\&pid=S010493131997000200002\&lng=en\&nrm=iso>. Acesso em 29 Jan. 2016.

HAKANI. O que é infanticídio? Disponível em: <http://www.hakani.org/pt/oque_e_infanticidio.asp>. Acesso em 01. fev. 2016.

HOLANDA, Marianna Assunção Figueiredo. Quem são os humanos dos direitos?: Sobre a criminalização do infanticídio indígena. Universidade de Brasília (UnB) (Dissertação de Mestrado em Antropologia). Orientadora: Rita Laura Segato, agosto, 2008. Disponível em: < http://repositorio.unb.br/bitstream/10482/5515/1/2008_MariannaAssuncaoFigueiredoHolanda .pdf>. Acesso em: 28 fev. 2016.

INSTITUTO BRASILEIRO DE GEOGRAFIA E ESTATÍSTICA (IBGE). Os indígenas no censo demográfico 2010: primeiras considerações com base no quesito cor e raça. Rio de Janeiro: IBGE, 2012.

JUNQUEIRA, Carmen. Antropologia indígena: uma (nova) introdução. 2 ed. São Paulo: Educ, 2008. 
KYMLICKA, Will. Cidadania multicultural: uma teoría liberal de los derechos de las minorias. Tradução de Carme Castells Auleda. Barcelona: Paidós Iberica, 1995.

MAGLIE, Cristina de. Los delitos culturalmente motivados: ideologias y modelos penales. Madrid: Marcial Pons, 2012.

MARTEL, Letícia de Campos Velho. Direitos fundamentais indisponíveis: os limites e os padrões do consentimento para a autolimitação do direito fundamental à vida. Dissertação de Doutoramento em Direito Público. Universidade do Estado do Rio de Janeiro. Orientador: Luis Roberto Barroso, Rio de Janeiro, 2010.

ORGANIZAÇÃO INTERNACIONAL DO TRABALHO (OIT). Convenção n 169 da OIT sobre povos indígenas e tribais. Conferência Geral da Organização Internacional do Trabalho. Genebra, 1989. Disponível em: < http://www.cpisp.org.br/htm/leis/instrum01.htm>. Acesso em: 03. Fev. 2016. (OIT, 1989)

ONU. Pacto Internacional dos Direitos Econômicos, Sociais e Culturais. 1992. Disponível em: https://www.oas.org/dil/port/1966\%20Pacto\%20Internacional\%20sobre\%20os\%20Direitos\% 20Econ\%C3\%B3micos, \%20Sociais\%20e\%20Culturais.pdf>. Acesso em: 03 fev. 2016.

ONU. Declaração das Nações Unidas sobre os Direitos dos Povos Indígenas. 2007 Rio de Janeiro: Nações Unidas, 2008. Disponível em: < http://www.un.org/esa/socdev/unpfii/documents/DRIPS_pt.pdf>. Acesso em 03 fev. 2016.

ONU. Declaração Universal dos Direitos Humanos. 1948. Rio de Janeiro: UNIC, 2009, p.05. Disponível em: < http://www.dudh.org.br/wp-content/uploads/2014/12/dudh.pdf>. Acesso em 03. Fev. 2016.

PEREIRA, Jane Reis Gonçalves. Interpretação constitucional e direitos fundamentais. Rio de Janeiro: Renovar, 2006.

PIOVESAN, Flávia. Direitos humanos e direito constitucional internacional. São Paulo: Saraiva, 2012.

SANTOS, Diego Junior da Silva; et al. Raça versus etnia: diferenciar para melhor aplicar. Dental Press J Orthod. maio-jun 2010. Disponível em: <http://www.scielo.br/pdf/dpjo/v15n3/15.pdf>. Acesso em 30 jan. 2016.

SANTOS. Luciano Gersem dos. O índio brasileiro: o que você precisa saber sobre os povos indígenas no Brasil de hoje. Brasília: Ministério da Educação, Secretaria de Educação Continuada, Alfabetização e Diversidade (SECAD) em parceria com o Museu Nacional, Laboratório de Pesquisas em Etnicidade, Cultura e Desenvolvimento (LACED), 2006. Disponível em: < http://unesdoc.unesco.org/images/0015/001545/154565por.pdf>. Acesso em 29 jan. 2016.

SANTOS, Rodrigo Mioto dos. Pluralismo, Multiculturalismo e Reconhecimento: uma análise constitucional do direito dos povos indígenas ao reconhecimento. Revista da Faculdade de Direito UFPR. Disponível em: 
http://ojs.c3sl.ufpr.br/ojs/index.php/direito/article/viewFile/7050/5026>. Acesso em: 10 fev. 2016.

SARLET, Ingo Wolfgang. As dimensões da dignidade da pessoa humana: construindo uma compreensão jurídico constitucional necessária e possível. Dimensões da dignidade: ensaios de Filosofia do Direito e Direito Constitucional. Porto Alegre: Livraria do Advogado, 2005.

SARAMENTO, José Augusto Nogueira. Breves reflexões sobre a cultural defense. Universidade de Lisboa. 2013. Disponível em: < http://www.revistas.unifacs.br/index.php/redu/article/view/3339/2398>. Acesso em 28 jan.16.

SEGATO, Rita Laura. Que cada povo teça os fios da sua história. Revista de Direito da Universidade de Brasília. v.1, n.1, janeiro-junho 2014.

SILVA, Jose Afonso da. Curso de Direito Constitucional Positivo. 15 ed. São Paulo: Malheiros, 1998.

SOUZA FILHO, Carlos Frederico Marés de. O renascer dos povos indígenas para o Direito. 6.ed. Curitiba: Juruá, 2009.

STRECK, Lenio Luiz. A morte de crianças pode ser considerada uma questão cultural?. Revista Consultor Jurídico (CONJUR). 29 out. 2015. Disponível em: < http://www.conjur.com.br/2015-out-29/senso-incomum-morte-criancas-questao-cultural>.

Acesso em 10 fev. 2016.

VIDAL, Lux. Morte e vida de uma sociedade indígena brasileira: os Kayapó-Xikrin do Rio Catete. São Paulo: Universidade de São Paulo, 1977.

COMISSÃO PRÓ-YANOMAMI. Infanticídio é uma tradição milenar dos Yanomami. 10 mar. $2015 . \quad$ Disponível em:< http://proyanomami.org.br/v0904/index.asp?pag=noticia\&id=3980>. Acesso em: 01 fev. 2016.

VILAÇA, Aparecida. Making kin out of others in Amazonia. Jornal of the Royal Anthropological Institute. Disponível em: <http://onlinelibrary.wiley.com/doi/10.1111/14679655.00007/abstract>. Acesso em 29 jan. 2016.

VILLAS BÔAS FILHO, Orlando. História, direito e a política indigenista brasileira do século XX. São Paulo: Metalivros, 2006.

WEINRIB, Lorraine. The postwar paradigm and american exceptionalism. Edição: Sujit Choudhry. Cambridge: Cambridge University Press. Disponível em: <http://ssrn.com/abstract=899131>. Acesso em 26 fev. 16. 